\title{
Response shift in quality of life assessment among cancer patients: A study from Iran
}

\author{
Bayan Hosseini ${ }^{1}$, Saharnaz Nedjat ${ }^{2 *}$, Kazem Zendehdel $^{3}$, Reza Majdzadeh ${ }^{2}$, Azam Nourmohammadi $^{3}$, \\ Ali Montazeri ${ }^{4}$
}

Received: 23 Jan 2017

Published: 22 Dec 2017

\begin{abstract}
Background: During the course of disease, particularly of chronic diseases, changes in internal standards cause certain changes in the estimation of quality of life (QOL). These changes indicate the phenomenon of 'response shift'. The present study aimed at assessing response shift in different scales of QOL in Iranian cancer patients.

Methods: To assess response shift through the 'then test' approach, we asked 211 cancer patients to complete the EORTC QLQ-C30 questionnaire at pretest (at the beginning of the study), posttest ( 3 months later), and then test (administered immediately after the posttest). Paired t test and Cohen's effect size were used for comparison.

Results: Response shift was significant in all 4 scales under study, i.e. fatigue, pain, emotional functioning, and general QOL $(\mathrm{p}<0.001)$. Fatigue, pain, and global QOL have deteriorated significantly with then test approach and emotional function was significantly improved.

Conclusion: We observed a response shift in Iranian cancer patients in our study. Thus, in light of the multifactorial nature of QOL and the effect of the response shift bias on different aspects of QOL changes, it is of utmost importance to keep this bias in mind when interpreting the results and managing cancer patients' treatment regimens.
\end{abstract}

Keywords: Quality of life, Response shift, Conventional change, Adjusted change, Then test

Copyright $\odot$ Iran University of Medical Sciences

Cite this article as: Hosseini B, Nedjat S, Zendehdel K, Majdzadeh R, Nourmohammadi A, Montazeri A. Response shift in quality of life assessment among cancer patients: A study from Iran. Med J Islam Repub Iran. 2017 (22 Dec);31:120. https://doi.org/10.14196/mjiri.31.120

\section{Introduction}

One of the main goals of cancer management is to preserve and improve patients' quality of life (QOL) (1), particularly in patients whose treatments are meant to palliate and not to cure the disease (2). QOL covers a wide range of concepts and has a multidimensional nature, which also includes objective and subjective dimensions (3). Hence, generally speaking, QOL may be defined as an individual's self-perceived satisfaction at any stage of life, which is related to satisfaction of different life scales (4). With the passage of time, health researchers distanced themselves from rigorous clinical measurements and began to measure the patient's self-assessment of his/her health status. Assessment of health-related QOL was applied to meet this end $(5,6)$. Self-reporting of side-effects and complications is one of the most important parameters applied in the assessment of standard and novel experi-

Corresponding author: Dr Saharnaz Nedjat, nejatsan@sina.tums.ac.ir

1. Department of Epidemiology and Biostatistics, School of Public Health, Tehran University of Medical Sciences, Tehran, Iran.

2. Epidemiology and Biostatistics Department, School of Public Health, Knowledge Utilization Research Center, Tehran University of Medical Sciences, Tehran, Iran.

3. Cancer Research Center, Cancer Institute of Iran, Tehran University of Medical Sciences, Tehran, Iran.

4. Mental Health Research Department, Institute for Health Sciences Research, ACECR, Tehran, Iran. mental therapeutic techniques in cancer patients (7) Based on the existing body of evidence, patients with chronic diseases may experience changes in the internal standards of QOL through the course of disease, which indicates the phenomenon of 'response shift' $(8,9)$. Response shift may occur as a result of severe holistic changes in health states that have taken place recently (9). Since the disease and cure are associated with symptoms and side effects, the patient learns to adapt to them. This may change the patient's internal standard of assessment, so the measurement of QOL changes may be biased (1012). In fact, during the course of the disease, adaptation to the disease may lead to changes in internal standards, level of health, and self-reported QOL. Eventually, the person will return to his/her usual settings and activities, whereas in fact the person may have undergone major

$\uparrow$ What is "already known" in this topic:

We evaluated the response shift in QOL changes in Iranian cancer patients.

\section{$\rightarrow$ What this article adds:}

This study was the first longitudinal prospective study to show response shift in patients in developing countries with a different background of QOL compared to developed countries. 
changes (13). These changes may take as long as 4 to 7 weeks (14). This condition results from a change in selfreporting of one's health status and should be taken into account in any study and/or clinical condition in which changes occur in health states; moreover, response shift should be kept in mind while interpreting QOL changes (15). In QOL studies, the important point is that the direction of response shift using the then test approach is very different in different studies and that a clear standard is lacking (16). To our knowledge, no study has been conducted on response shift in developing countries including Iran and the fact that QOL is a cultural construct necessitates this study among Iranian patients. Here, in addition to evaluating the response shift in QOL changes, we have also examined the association between background and clinical factors in each of the QOL scales and response shift. The results of this study may help in the interpretation and analysis of QOL research studies.

\section{Methods}

\section{Population under study}

A prospective cohort study was conducted in which patients were followed-up 3 months after the study began. The goal was to investigate response shift on QOL in cancer patients. The population under study consisted of 211 patients with different types of cancer, who were included in the study during April 2013 and June 2014. Samples were selected from patients attending Cancer Institute of Imam Khomeini hospital, who had received their pathology reports no longer than 8 weeks. After explaining the study procedure to the patients and confirming the presence of the inclusion criteria, the patients signed the written consent forms. Convenience sampling was continued until the necessary sample size was reached.

The inclusion criteria were as follow: age $>18$ years, not having participated in another QOL study simultaneously, not having a chronic psychiatric disease simultaneously, not having another chronic disease simultaneously, and the ability to respond during the interview.

The EORTC QLQ-C30 questionnaire was completed for the patients at pretest, posttest, and then test. In the then test approach, an evaluation was done at the beginning of the study at pretest. Then, another assessment was done 3 months later (posttest). When standard methods are applied to assess QOL changes, the difference between pretest and posttest scores are referred to as 'conventional changes'. The then test approach is a 'retrospective' evaluation of the pretest (17-19), ie, the patient is asked to recall the past and score his/her QOL at the time with his/her current standards (20). The adjusted changes indicate the difference between the then test and the posttest, reflecting the QOL changes following response shift and 'adjusted treatment or time effect', reflecting the changes in QOL after removing the effect of response shift bias $(21,22)$. In most QOL studies, where response shift is measured through the then test approach and the EORTC QLQ-C30 questionnaire, the scales of fatigue, pain, emotional functioning, and global QOL are considered in assessing RS $(16,23)$. We, too, chose these 4 scales for our study.
Prior to the study, the interviewers were taught how to complete the forms. Then, their skills were evaluated by the researcher. Then, the aforementioned questionnaire was completed by the patients at the beginning of the study, at pretest. Then, the patients were again interviewed twice, once for the conventional posttest and once for the then test, 3 months later. The first evaluation was done during outpatient visits or indoor admissions, and the second evaluation was conducted 3 months later. Before the interview, the interviewer ensured that the patient completely understood the concept of the then test. Then, s/he would ask the patient to explain her/his understanding of the subject. Thereafter, the patients were asked the following questions: "Are you aware of your disease?", "Do you know why you have been admitted?", "Do you know why you have undergone surgery?" The questions had to be asked in a clear manner and not causing confusion in the patients if they were unaware of their disease. The questionnaire was completed by the interviewer in a quiet environment. The patient would be considered a loss to follow-up if 3 follow-up attempts were unsuccessful.

\section{Ethical considerations}

This study has been approved by the Ethics Committee of Tehran University of Medical Sciences (project number: 22758). Written informed consent was taken from all participants. Participants could leave the study at any time they wished. Participation in the study did not harm the patients. Moreover, leaving the study or non-participation did not affect the treatment procedure.

\section{Data collection tool}

The EORTC QLQ-C30 questionnaire is a 30-item questionnaire that assesses QOL in cancer patients. It includes a general scale on QOL and global health status, 5 functional scales (physical, role, emotional, cognitive, and social), 3 symptom scales (fatigue, nausea and vomiting, and pain), and 6 single units (dyspnea, insomnia, appetite loss, constipation, diarrhea, and financial difficulties). The validity and reliability of this questionnaire have already been evaluated in Iran (24). The items of the functional and symptoms scales are scored from 1 to 4 and those of the global health status/QOL scale are scored from 1 to 7 . Based on the following guide, all scales are allocated scores 0 to 100 , such that the highest functional scale score indicates the highest health score or functional level, the highest global health status/QOL scale score indicates the highest level of QOL, and the highest symptoms scale score indicates the most number of problems and disease signs (25). The higher the scores in the following functional scales, the better the patient's QOL (physical, role, social functioning, emotional functioning, cognitive scales, financial difficulties, and global health status). The higher the scores in the following scales, the worse the patient's QOL (fatigue, nausea and vomiting, pain, dyspnea, appetite loss, constipation, diarrhea, and financial difficulties).

\section{Statistical analysis}

All patients whose QoL had been assessed at the begin- 
ning of the study were reassessed at follow-up. Data were analyzed using STATA-12 \& SPSS-18. Mean, standard deviation (SD), and range were calculated for all the continuous variables. Frequency distribution (number and percentage) was reported for the discrete variables. Paired $t$ test was used to examine the difference between the post and then tests. Here, we evaluated response shift through the then test approach. Response shift was calculated from the difference between then test and pretest (26). Also, conventional changes were calculated from the difference between posttest and pretest. The difference between posttest and then test, which removes the induced effect of RS on treatment and estimates the treatment effect without confounding, was also calculated. Cohen's effect size was estimated using the equation below to calculate the magnitude of the difference between the then test and pretest. Cohen's effect size is interpreted as follows: $0.5>\mathrm{d}>2.0$, $0.8>d>5.0$, and $d>0.8$ indicate small effect size, average effect size, and large effect size, respectively. The equation for calculating effect size is as follows (27):

$$
d=\frac{\text { Difference of mean scores }}{\text { Difference of standard deviation }}
$$

\section{Results}

\section{Participants' particulars}

A total of 211 patients were included in this cohort study. These patients had breast, gastrointestinal tract (GIT), lung, bladder, genital organs, and head and neck cancers. The majority of the patients had either breast $(40.6 \%)$ or GI $(30.1 \%)$ cancers. Their age ranged from 20 to 84 years, with a mean $\pm \mathrm{SD}$ of $51.3 \pm 13.9$ years. Response rate was $87.3 \%(n=184)$ at the time of the followup (3 months later). We had $27(12.7 \%)$ cases of loss to follow-up, of them $10(4.7 \%)$ died and $17(8.0 \%)$ did not wish to continue with the study. Of the patients, $82.3 \%$ had been informed of their illness. Almost 95\% $(n=135)$ of patients' histopathology were of the carcinoma type. The spread of the cancer was localized in 37.4\%, metastasized in $39.3 \%$, regional in $11.9 \%$, and uncertain in $11.4 \%$ of the cases (Tables 1 and 2).

QOL changes have been illustrated in Table 3. The mean difference of physical functioning (PF) had significantly decreased by -7.57 (95\% CI: 3.15 - 11.9) from pretest to posttest. In other words, the individual's physical functioning had decreased over time. On the other hand, the mean posttest - pretest changes were not significant in the role, social, and cognitive functioning (CF) scales.

Table1. Socio-demographic characteristics of the participants at baseline $(\mathrm{n}=211)$

\begin{tabular}{|c|c|c|}
\hline Variable & & Descriptive statistic \\
\hline \multicolumn{3}{|l|}{ Education status (years) } \\
\hline $\operatorname{Mean}(\mathrm{SD})$ & & $7.16(5.22)$ \\
\hline Range & & $0-17$ \\
\hline \multicolumn{3}{|c|}{ Constructed area per capita $\left(\mathrm{m}^{2}\right)$} \\
\hline $\operatorname{Mean}(\mathrm{SD})$ & & $34.29(33.64)$ \\
\hline Range & & $2.4-300$ \\
\hline \multicolumn{3}{|l|}{ Room Num per capita } \\
\hline $\operatorname{Mean}(\mathrm{SD})$ & & $0.67(0.50)$ \\
\hline Range & & $0.16-4$ \\
\hline \multicolumn{3}{|c|}{ Household dimension (Person) } \\
\hline \multicolumn{2}{|l|}{$\operatorname{Mean}(\mathrm{SD})$} & $3.57(1.67)$ \\
\hline \multicolumn{2}{|l|}{ Range } & $1-10$ \\
\hline $\begin{array}{l}\text { Table 2. Socio-demographic } \\
\text { Variable }\end{array}$ & $\frac{1 \text { ical characteristics of } t}{\text { Category }}$ & $\frac{\text { ants at baseline }(\mathrm{n}=21}{\mathrm{N}(\%)}$ \\
\hline \multirow[t]{4}{*}{ Marital status } & Married & $179(84.83)$ \\
\hline & Single & $15(7.11)$ \\
\hline & Widow & $14(6.64)$ \\
\hline & Separated & $5(1.42)$ \\
\hline \multirow[t]{4}{*}{ House status } & Owner & $141(67.14)$ \\
\hline & Rent & $55(26.19)$ \\
\hline & Parents & $12(5.71)$ \\
\hline & Other & $2(0.95)$ \\
\hline \multirow[t]{5}{*}{ Self-rated economic status } & Excellent & 0 \\
\hline & Very good & 0 \\
\hline & Good & $24(11.43)$ \\
\hline & Not bad & $129(61.43)$ \\
\hline & Bad & $57(27.14)$ \\
\hline \multirow[t]{8}{*}{ Cancer Type } & Breast & $85(40.67)$ \\
\hline & GI & $63(30.14)$ \\
\hline & Reproductive organs & $22(10.53)$ \\
\hline & Lung & $7(3.35)$ \\
\hline & Bladder & $8(3.83)$ \\
\hline & Prostate & $6(2.87)$ \\
\hline & Head and neck & $16(7.66)$ \\
\hline & Sarcoma & $2(0.96)$ \\
\hline \multirow{4}{*}{$\begin{array}{l}\text { Spread of tumor at the } \\
\text { time of interview }\end{array}$} & Local & $79(37.44)$ \\
\hline & Regional & $25(11.85)$ \\
\hline & Metastasis & $83(39.34)$ \\
\hline & Uncertain & $24(11.37)$ \\
\hline
\end{tabular}




\begin{tabular}{|c|c|c|c|c|c|c|}
\hline & & \multirow{2}{*}{$\begin{array}{c}\begin{array}{c}\text { QOL at baseline } \\
\text { (pre test) }\end{array} \\
\text { Mean (SD) }\end{array}$} & \multirow{2}{*}{$\begin{array}{c}\text { QOL } 3 \text { months later } \\
\text { (post test) } \\
\text { Mean (SD) }\end{array}$} & \multicolumn{3}{|c|}{$\begin{array}{l}\text { Post -test-minus-Pre-test } \\
\text { (Conventional change) }\end{array}$} \\
\hline & & & & Mean difference (SD) & $95 \% \mathrm{CI}^{*}$ & $\mathrm{p}^{*}$ \\
\hline \multicolumn{7}{|l|}{ Functional scales } \\
\hline Physical functioning & $\mathrm{PF}$ & $70.71(29.26)$ & $62.76(26.17)$ & $-7.57(30.29$ & {$[-3.15,-11.99]$} & $<0.001 *$ \\
\hline Role functioning & $\mathrm{RF}$ & $69.66(33.43)$ & $68.04(30.59)$ & $-1.73(42.89)$ & {$[4.53,-8.01]$} & 0.5849 \\
\hline Emotional functioning & $\mathrm{EF}$ & $53.56(27.90)$ & $56.90(27.98)$ & $2.79(32.80)$ & {$[7.63,-2.04]$} & 0.2561 \\
\hline Cognitive functioning & $\mathrm{CF}$ & $82.61(24.58)$ & $80.57(25.96)$ & $-2.68(30.67)$ & {$[1.82,-7.19]$} & 0.2418 \\
\hline Social functioning & $\mathrm{SF}$ & $72.69(29.76)$ & $78.26(27.73)$ & $4.35(31.82)$ & {$[9.03,-0.32]$} & 0.0682 \\
\hline \multicolumn{7}{|l|}{ Global health status /QoL } \\
\hline Global health status/QoL & QL & $54.73(23.10)$ & $58.24(24.32)$ & $2.94(27.43)$ & {$[-1.07,6.97]$} & 0.1503 \\
\hline \multicolumn{7}{|l|}{ Symptom scales / items } \\
\hline Fatigue & FA & $40.54(29.81)$ & $55.31(28.56)$ & $15.71(45.33)$ & {$[22.36,9.06]$} & $<0.001 *$ \\
\hline Nausea and vomiting & NV & $12.46(23.61)$ & $16.56(26.55)$ & $4.72(31.52)$ & {$[9.35,0.08]$} & $0.046^{*}$ \\
\hline Pain & $\mathrm{PA}$ & $37.59(32.81)$ & $39.50(31.48)$ & $1.93(38.54)$ & {$[7.58,-3.71]$} & 0.500 \\
\hline Dyspnoea & DY & $14.12(25.39)$ & $20.87(29.37)$ & $6.63(32.47)$ & {$[11.39,1.86]$} & $0.006 *$ \\
\hline Insomnia & $\mathrm{SL}$ & $33.49(37.01)$ & $32.96(37.73)$ & $-0.18(41.53)$ & {$[6.25,-5.89]$} & 0.953 \\
\hline Appetite loss & Ap & $33.49(49.03)$ & $32.41(37.31)$ & $0.54(50.71)$ & {$[7.96,-6.86]$} & 0.884 \\
\hline Constipation & $\mathrm{CO}$ & $24.92(36.98)$ & $23.33(34.86)$ & $-2.04(43.00)$ & {$[4.29,-8.39]$} & 0.525 \\
\hline Diarrhoea & DI & $9.79(25.38)$ & $13.44(28.92)$ & $3.13(34.73)$ & {$[8.22,-1.96]$} & 0.227 \\
\hline Financial difficulties & FI & $55.76(41.30)$ & $56.72(38.15)$ & $1.47(43.86)$ & {$[7.90,-4.95]$} & 0.652 \\
\hline
\end{tabular}

*The bolded confidence intervals indicate a $95 \%$ significance level

-Negative changes in the functional scales (physical, role, social \& emotional functioning), cognitive and global QOL scales indicate that the patient's QOL has worsened

-Negative changes in the fatigue, nausea \& vomiting, pain, insomnia, dyspnea, appetite loss, constipation and financial difficulties scales indicate an improvement in the patient's overall symptoms

In the items scale, the means of nausea and dyspnea had increased significantly as 4.73 (95\% $\mathrm{CI}$ : $-9.35--0.08)$ and $6.63(95 \% \mathrm{CI}:-11.39-1.86)$, respectively. In the other words, the patients reported greater nausea and dyspnea (DY) 3 months later at posttest. Insomnia (SL) and constipation $(\mathrm{CO})$ had become less over time, while diarrhea had slightly increased at posttest. Nonetheless, neither of the aforementioned changes was significant. The mean score of financial difficulties increased at posttest, but this increase was not statistically significant.

\section{Response shift}

Table 4 demonstrates the effect of response shift, conventional changes, and adjusted changes in fatigue (FA), pain (PA), emotional functioning (EF), and global quality of life scales. The response shift in all the aforementioned scales was significant. The negative direction of RS in the emotional functioning scale indicated its improvement. Moreover, the positive direction of RS in the fatigue and pain scales indicated their worsening. The positive direc- tion of the global QOL scale reflected a retrospective worsening of QOL.

The mean EF of patients was better in both the posttest and then test compared to the pretest. The mean EF changes were significant through the then test approach 14.45 (95\% CI: 11.22-17.67).

The fatigue mean had significantly increased from pretest to posttest, but had significantly decreased in the then test when compared to the pretest. The fatigue mean changes evaluated through the conventional approach revealed a worsening of the situation at posttest. These changes were significant (15.71 (95\%CI: 22.36-9.06)) and showed a worsening of the patients' fatigue state. However, the then test approach showed a significant worsening of fatigue mean in the then test, with a mean difference of 11.7 (95\%CI: 7.22-16.23).

In the pain scale, conventional changes had not changed significantly over time, whereas the then test approach showed that the condition had worsened. Through the then test approach, the mean difference was found to be -10.8

Table 4. Mean scores and standard deviations (SD) of the pretest and the then test, paired t-test results and effect sizes(d)

\begin{tabular}{|c|c|c|c|c|c|c|c|c|c|c|}
\hline & \multicolumn{3}{|c|}{$\begin{array}{l}\text { Post -test-minus- Pre -test } \\
\text { (Conventional change) }\end{array}$} & \multicolumn{3}{|c|}{$\begin{array}{l}\text { Post -test-minus-Then-test } \\
\text { (Adjusted change) }\end{array}$} & \multicolumn{4}{|c|}{$\begin{array}{l}\text { Then-test-minus-Pre-test } \\
\text { (Response Shift) }\end{array}$} \\
\hline & $\begin{array}{l}\text { Mean } \\
(\mathrm{SD})\end{array}$ & $\mathrm{p}^{*}$ & $95 \% \mathrm{CI}$ & Mean(SD) & $\mathrm{p}^{*}$ & $95 \% \mathrm{CI}$ & $\begin{array}{l}\text { Mean(S } \\
\text { D) }\end{array}$ & $\mathrm{p}^{*}$ & $95 \% \mathrm{CI}$ & $\mathrm{d}^{* *}$ \\
\hline \multicolumn{11}{|l|}{$\begin{array}{l}\text { Global health } \\
\text { status }\end{array}$} \\
\hline $\begin{array}{l}\text { Global health } \\
\text { status/QoL }\end{array}$ & $\begin{array}{c}2.94 \\
(27.43)\end{array}$ & 0.1503 & $\begin{array}{l}{[6.97,-} \\
1.07]\end{array}$ & $\begin{array}{l}-18.61 \\
(41.49)\end{array}$ & $<0.001^{*}$ & $\begin{array}{c}{[-24.71,-} \\
12.50]\end{array}$ & $\begin{array}{l}-15.64 \\
(42.10)\end{array}$ & $<0.001 *$ & $\begin{array}{c}{[-21.84,-} \\
9.45]\end{array}$ & -0.14 \\
\hline $\begin{array}{l}\text { Functional } \\
\text { scales }\end{array}$ & & & & & & & & & & \\
\hline $\begin{array}{l}\text { Emotional } \\
\text { functioning }\end{array}$ & $\begin{array}{c}2.79 \\
(32.80)\end{array}$ & 0.2561 & $\begin{array}{c}{[7.63,-} \\
2.04]\end{array}$ & $\begin{array}{c}11.73 \\
(30.55)\end{array}$ & $<0.001^{*}$ & $\begin{array}{l}{[7.22} \\
16.23]\end{array}$ & $\begin{array}{l}14.45 \\
(21.74)\end{array}$ & $<0.001^{*}$ & $\begin{array}{l}{[11.22,} \\
17.67]\end{array}$ & 0.11 \\
\hline Symptom scales & & & & & & & & & & \\
\hline Fatigue & $\begin{array}{c}15.71 \\
(45.33)\end{array}$ & $<0.001 *$ & $\begin{array}{c}{[22.36} \\
9.06]\end{array}$ & $\begin{array}{l}-27.00 \\
(46.57)\end{array}$ & $<0.001^{*}$ & $\begin{array}{c}{[-33.87,-} \\
20.13]\end{array}$ & $\begin{array}{l}-11.73 \\
(31.48)\end{array}$ & $<0.001^{*}$ & $\begin{array}{c}{[-16.37,-} \\
7.08]\end{array}$ & -0.50 \\
\hline Pain & $\begin{array}{c}1.93 \\
(38.54)\end{array}$ & 0.5005 & $\begin{array}{l}{[7.58,-} \\
3.71]\end{array}$ & $\begin{array}{c}12.84 \\
(35.76)\end{array}$ & $<0.001^{*}$ & $\begin{array}{c}{[-18.12,-} \\
7.57]\end{array}$ & $\begin{array}{l}-10.80 \\
(30.67)\end{array}$ & $<0.001^{*}$ & $\begin{array}{c}{[-15.32,-} \\
6.27]\end{array}$ & -0.05 \\
\hline
\end{tabular}

*indicate levels of significance $\mathrm{p}<0.05$

**Effect sizes are calculated according to the formula: mean (difference score)/SD (difference score)

Scalesafter linear transformation runs from 0 to 100 , higher values indicating a higher scale level. 
(95\%CI: -15.32- -6.37). Furthermore, the difference of adjusted changes between posttest and then test was equal to 12.84 (95\% $\mathrm{CI}$-18.12- -7.57), indicating an increase in patients' pain.

Conventional changes between pretest and posttest in the QOL scale were statistically insignificant, whereas these changes were significant through the then test approach. The mean difference between the pretest and then test was $15.6 \quad(95 \% \quad$ CI: $-21.84-\quad-9.45)$, with a -0.14 measure of effect, indicating the worsening of QOL. Moreover, the adjusted changes of QOL at posttest as opposed to then test yielded a mean difference of -18.6 (95\% CI: -24.71- -12.50), indicating a worsening of QOL.

\section{Discussion}

One of the most important methods of measuring the treatment effect is measuring QOL changes in patients. Response shift is one of those biases that can affect psychological standard indices and change their reliability and validity. Therefore, removing bias from ongoing studies is of paramount importance.

Our cohort study included 211 newly-diagnosed or treated-for cancer patients. We observed evidence hinting to the instability of internal standards of different QOL scales after diagnosing the cancer. It seems that the sideeffects of treatment or the effect of the diagnosis on the patient have adequately brought about the response shift. Here, we examined changes in patients' internal standards in 4 scales of fatigue, pain, emotional functioning, and global QOL. Results of the first 3 scales conformed to the hypothesis; however, those of global QOL did not.

In our study, patients retrospectively felt less fatigued compared to the pretest time. Sharp et al. observed that fatigue had increased with the passage of time (28). We observed less fatigue at then test than at pretest and posttest. On the whole, it may be stated that patients had adapted themselves to higher levels of fatigue, reporting lower levels of fatigue in the then test as opposed to pretest and posttest retrospectively. Moreover, the mean fatigue score of posttest was higher than that of pretest and then test. Therefore, the increase in fatigue in then testposttest (adjusted changes)- was greater than posttest - pretest (conventional changes). Visser et al. did not observe any changes in fatigue over time and found the difference between pretest and posttest means (conventional changes) to be insignificant. Patients reported less fatigue before the treatment than at then test. Further, the then test - posttest difference was significant at a $\mathrm{p}<0.005$. Hence, patients felt more fatigued after treatment than before it (30). Sprangers et al. found the difference between pretest and the then test to be statistically significant in the fatigue scale $(p<0.000)(14)$. Thus, it can be stated that during the course of disease and due to the side effects of treatment, patients feel more fatigued as their immune systems become suppressed.

In our study, the patients' pain had increased at posttest compared to pretest, and the mean pain changes measured through the conventional approach were not significant. However, the pain they reported retrospectively at pretest was less than the pretest and posttest. On average, patients reported greater pain at pretest; if patients had adapted to the level of pain they felt at posttest, then we would have expected to see an increase in symptoms at pretest, retrospectively. However, contrary to our expectation, in this study, the patients' mean pain level was lower at then test than at pretest and posttest. Therefore, the mean pain score in 'then test - posttest (adjusted changes)- was greater than the mean pain score in posttest - pretest (conventional changes)- and in then test - pretest (response shift); the mean pain score for adjusted changes after adjusted treatment or time effect was greater than the mean pain score for response shift. Visser et al. observed greater pain in then test than in pretest and observed a very small RS effect for patients' physical pain $(\mathrm{p}<0.01$; pre $<$ then) (19). The latter findings are in agreement with ours.

In the emotional functioning scale, EF was better at posttest than at pretest and was better at then test than at pretest and posttest, reflecting the patients' adaptation to worsening emotional conditions, which was an expected finding. Therefore, the EF changes in posttest- then test after adjusted treatment or time effect- were better than the EF changes in posttest - pretest (conventional changes). Conventional changes were not significant. Nevertheless, patient recalibration may have taken place under the influence of different groups of patients whose EF had worsened, remained stable, improved, or became neutral.

A cohort study conducted on breast cancer patients showed significant changes in health and QOL from the start of the study till the end of the first treatment/or/admission period (conventional changes, $\mathrm{p}<0.0001$ ) (13). Here, these changes were statistically insignificant although the patients' QOL had slightly improved through the conventional approach. Another study examined 22 adolescent cancer patients considering the response shift effect; the patients' QOL worsened 3 months after the intervention, which appears to conform to the RS phenomenon. Response shift was significant for the global QOL scale with a mean (SD) of 0.6 (1) (31).

One of the limitations of this study was the problem of explaining the concept of RS and the study procedure to patients.

Furthermore, patients usually expect to feel better after receiving their required treatments. Perhaps, some of their feeling of improvement following treatment may be attributed to this expectation and not to the pure effect of treatment. Thus, even though RS may have desirable psychological effects for the patient to adapt to his/her ongoing situation, it may have a confounding effect on the assessment of treatment effect or side-effects. This in turn reduces the validity and sensitivity of the study results. Consequently, the effect or side effect of medications and/or therapeutic methods cannot be adequately relied on.

\section{Conclusion}

This study was the first longitudinal prospective study to evaluate response shift in developing countries. Moreover, the multidimensional nature of QOL warrants the need to take the bias effect of RS on different aspects of QOL into account during interpretation of findings. There- 
fore, when managing cancer patients' treatments, we should not only take physical aspects into account, but we should also consider other health and QOL aspects improve their global health and QOL and to try to reduce their pain and suffering.

\section{Conflict of Interests}

The authors declare that they have no competing interests.

\section{References}

1. Brow JP, McGee HM, O'Boyle CA. Conceptual approaches to the assessment of quality of life. Psychol Health. 1997;12(6):737-751.

2. Pratheepawanit N, Salek M, Finlay I. The applicability of quality-oflife assessment in palliative care: comparing two quality-of-life measures. Palliat. Med. 1999;13(4):325-334.

3. Abdollahpour I, Salimi Y, Nedjat S, Jorjoran Shushtari Z. Quality of lifeand effective factors on it among governmental staff in boukan. $\mathrm{U}$ M J. 2011;22(1): 40-47.

4. Campbell A, Converse, PE, Rodgers WL. The quality of American life: Perceptions, evaluations, and satisfactions: RSF. 1976.

5. de Haan Rd, Aaronson N, Limburg M, Hewe RL, Van Crevel H. Measuring quality of life in stroke. AHA. 1993;24(2):320-327.

6. Duncan PW, Samsa GP, Weinberger M, Goldstein, LB, Bonito A, Witter DM, et al. Health status of individuals with mild stroke. AHA. 1997;28(4):740-745

7. Campbell DT, Stanley JC, Gage NL. Experimental and quasiexperimental designs for research: Houghton Mifflin Boston; 1963.

8. Sprangers M, Schwartz C. The challenge of response shift for qualityof-life-based clinicaloncology research. Ann Oncol. 1999;10(7):747749 .

9. Sprangers MA, Schwartz CE. Integrating response shift into healthrelated quality of life research: a theoretical model. Soc. Sci. Med. 1999;48(11):1507-1515.

10. Breetvelt I, Van Dam F. Underreporting by cancer patients: the case of response-shift. Soc. Sci. Med. 1991;32(9):981-987.

11. Andrykowski MA, Hunt JW. Positive psychosocial adjustment in potential bone marrow transplant recipients: Cancer as a psychosocial transition. Psychooncology. 1993;2(4):261-276.

12. Kagawa-Singer M. Redefining health: living with cancer. Soc. Sci. Med. 1993;37(3):295-304.

13. Dabakuyo T, Guillemin F, Conroy T, Velten M, Jolly D, Mercier M, et al. Response shift effects on measuring post-operative quality of life among breast cancer patients: a multicenter cohort study. Qual Life Res.2013;22(1):1-11.

14. Sprangers MA, Van Dam FS, Broersen J, Lodder L, Wever L, Visser $\mathrm{MR}$, et al. Revealing response shift in longitudinal research on fatigue: the use of the thentest approach. Acta Oncol. 1999;38(6):709-718.

15. Ahmed S, Mayo NE, Corbiere M, Wood-Dauphinee S, Hanley J, Cohen R. Change in quality of life of people with stroke over time: True change or response shift? Qual Life Res. 2005;14(3): 611-627.

16. Schwartz CE, Bode R, Repucci N, Becker J, Sprangers MA, Fayers PM. The clinical significance of adaptation to changing health: a metaanalysis of response shift. Qual Life Res. 2006;15(9):1533-1550.

17. Howard GS, Ralph KM, Gulanick NA, Maxwell SE, Nance DW, Gerber SK. Internal invalidity in pretest-posttest self-report evaluations and a re-evaluation of retrospective pretests. Appl Psychol Meas. 1979;3(1): 1-23.

18. Wiklund I. Assessment of patient-reported outcomes in clinical trials: the example of health-related quality of life. Fundam Clin Pharmacol. 2004;18(3):351-363

19. Visser MRM, Oort FJ, Sprangers MAG. Methods to detect response shift in quality of life data: a convergent validity study. Qual Life Res. 2005, 14(3): 629-639

20. Hosseini B, Nedjat S, Zendehdel K, Majdzadeh SR, Motazeri A. Response Shift in Measuring Health-related Quality of Life as Pertaining to Health: Concepts, Definitions, and Challenges. BCCR. 2013;5(4):2-9.

21. Rees J, Clarke MG, Waldron D, O'Boyle C ,Ewings P, MacDonagh RP. The measurement of response shift in patients with advanced prostate cancer and their partners. Health Qual Life Outcomes. 2005;3(21):1-8.
22. Schwartz CE, Sprangers MA. Guidelines for improving the stringency of response shift research using the thentest. Qual Life Res. 2010;19(4):455-464.

23. Kvam AK, Wisloff F, Fayers PM. Minimal important differences and response shift in health-related quality of life; a longitudinal study in patients with multiple myeloma. Health Qual Life Outcomes. 2010;8(1):79.

24. Montazeri A, Harirchi I, Vahdani M, Khaleghi F, Jarvandi S, Ebrahimi M, et al. The European Organization for Research and Treatment of Cancer Quality of Life Questionnaire (EORTC QLQC30): translation and validation study of the Iranian version. Support Care Cancer. 1999;7(6):400-406.

25. Fayers PM, Aaronson NK, Bjordal K, Grønvold M, Curran D, Bottomley A. EORTCQLQ-C30 scoring manual. Eur. J. Cancer. 2001.

26. Schwartz CE, Sprangers MA. Methodological approaches for assessing response shift in longitudinal health-related quality-of-life research. Soc. Sci. Med. 1999;48(11):1531-1548.

27. Cohen J. Statistical power analysis for the behavioral sciences: Academic Pr. 2013.

28. Sharp HM, List M, MacCracken E, Stenson K, Stocking C, Siegler M. Patients' priorities among treatment effects in head and neck cancer: evaluation of a new assessment tool. Head Neck. 1999; 21(6):538-546.

29. Visser MR, Smets E, Sprangers MA, de Haes HJ. How response shift may affect the measurement of change in fatigue. J Pain Symptom Manage. 2000;20(1):12-18.

30. Hagedoorn M, Sneeuw KC, Aaronson NK. Changes in physical functioning and quality of life in patients with cancer: response shift and relative evaluation of one's condition. J Clin Epidemiol. 2002;55(2):176-183

31. Schwartz CE, Feinberg RG, Jilinskaia E, Applegate JC. An evaluation of a psychosocial intervention for survivors of childhood cancer: paradoxical effects of response shift over time. Psychooncology.1999;8(4):344-354. 